\title{
İmmunosenescence and The İmportance of İnfluenza and Pneumococcal Vaccine in Elderly?
}

\author{
İmmün Yaşlanma ve Yaşlılarda İnflüenza ve Pnömokok Aşısının \\ Önemi
}

Halil İbrahim Erdoğgu ${ }^{1}{ }^{*}$, Can Öner ${ }^{2}$

\begin{abstract}
The vaccination of the elderly is generally ignored and their vaccination is insufficient. However, infectious diseases such as influenza and pneumococcus can be prevented or alleviated by vaccination. The "immune aging" ("immunosenescence") results in a decrease in the functions of the humoral and cellular immune systems in the elderly. Therefore, susceptibility to infections is increasing such as influenza and pneumococcus. Vaccination is effective and protective in these infections as it is important for many infections. If there is no contraindication or immunodeficiency, influenza and pneumococcal vaccinations are recommended for those aged 65 years and over by CDC (Center for Disease Control and Prevention). In this review, the importance of vactination against influenza and pneumococcal infections was discussed in the light of current studies.
\end{abstract}

Key words: Aged, İmmunosenescence, Influenza vaccines, Pneumococcal vaccines

\section{ÖZET}

Yaşılıarın aşılanması genel olarak göz ardı edilmekte olup aşılanmaları yetersizdir oysa influenza ve pnömokok gibi enfeksiyöz hastalıklar ve komplikasyonları, aşı ile önlenebilir ya da hafifletilebilirler. Yaşlılarda immün yaşlanma (immunosenescence) sonucu humoral ve hücresel immün sistem fonksiyonlarında azalma olmaktadır dolayısıyla/Bu nedenle influenza ve pnömokok gibi enfeksiyonlara karşı hassasiyet artmaktadır. Birçok enfeksiyon etkenine karşı aşılanmanın önemi olduğu gibi bu enfeksiyonlarda da aşılanma etkili ve koruyucudur. Eğer bir kontrendikasyon ya da immün yetmezliği yoksa CDC (Center for Disease Control and Prevention) tarafindan 65 yaş ve üzeri olanlara, influenza ve pnömokok aşısı önerilmektedir. Bu derlemede, güncel çalışmalar 1şığında immün yaşlanma ve bununla ilişkili olarak inflüenza ve pnömokok enfeksiyonlarına karşı aşılanmanın önemi tartışıld1.

Anahtar kelimeler: Yaşlanma, İmmün yaşlanma, İnflüzenza aşısı, pnömokok aşısı

Received Date: 22.07-2019, Accepted Date: 31.08-2019

*1 Kafkas niversitesi Tıp Fakültesi İç Hastalıkları AD

*22Kartal Dr Lütfi Kırdar Eğiti ve Araştırma Hastanesi Aile Hekimliği Kliniği*

Address for Correspondence / Yazışma Adresi: Can Öner, Kartal Dr Lütfi Kırdar Eğiti ve Araştırma Hastanesi Aile Hekimliği Kliniği

E-mail: trcanoner@yahoo.com

Erdoğdu İ.E., Öner C. İmmün yaşlanma ve yaşlılarda inflüenza ve pnömokok aşısının önemiTJFMPC, $2019 ; 13$ (4): 567-572.

DOI: $10.21763 / \mathrm{tjfmpc} .653275$ 


\section{Gİiş̧}

Dünyada 60 yaş ve üzeri olan insanların sayısı, 2015 yılında yaklaşık 900 milyonken 2050 y1lında 2 milyara ulaşacağı öngörülmektedir. ${ }^{1}$ Ülkemiz açısından bakıldığında Türkiye İstatistik Kurumu (TUIK) verilerine göre 2017 yılında 65 yaş ve üzeri olanların nüfusa oran $1 \% 8,5$ civarında olup bu oranın giderek artacağı öngörülmektedir. ${ }^{2}$

Yaşlilarda timusun involüsyonu ile $\mathrm{T}$ hücrelerinin sayısında ve CD4/CD8 oranında azalma yaşanmakta, antikor yanıtı sağlayan B-hücreleri ve antijen sunumundan sorumlu dendritik hücreler etkilenmektedir. Bunlardan başka $\mathrm{T}$ hücre repertuarının çeşitliliğinde azalma olmakta ve enfekte hücreleri elimine eden natürel killer hücreler ile monosit ve makrofajlar da etkilenmektedir. "İmmün yaşlanma" ya da "İmmunosenescence" olarak tabir edilen bu değişiklikler, yaşlilarda enfeksiyonlara karşı duyarlılığa yol açmaktadır. ${ }^{3-5}$

Yaşlanmayla oksidatif strese karş1 koruyucu ve hücresel disfonksiyonu azaltan ayrıca yaşla ilişkili patolojilerden koruyan "Sirtuinler" ya da kısaca "SIRT(1-6)"olarak adlandırılan NAD (Nicotinamide Adenine Dinucleotide) bağımlı deasetilasyon enzimatik reaksiyonları, olumsuz etkilenebilmektedir. Mitokondrial fonksiyonlarda ve DNA tamirinde olumlu etki yaptığı ileri sürülen SIRT1-6 proteinlerinin yaşlanma ile azaldı $\breve{g}_{1}$ dolayısıyla komorbiditelere eğilimin arttığı ileri sürülmektedir. ${ }^{6-10}$

Yaşam boyunca yalnızca influenza ve pnömokok gibi enfeksiyon etkenleri değil aynı zamanda Herpes simplex, Varisella zoster, Epsteinbarr ve Sitomegalovirüs gibi virüslerle de karşılaşılmakta ve latent enfeksiyonlar oluşabilmektedir. Özellikle 80 yaş ve daha üzeri olan kişilerde, CMV etkili olmaktadır. Bu durum, yaşlılarda kronik bir şekilde düşük düzeyde inflamasyona neden olmaktadır. ${ }^{11}$

Dünyada her yıl 3,5 milyon kadar inflüenza enfeksiyonu olgusu görülmekte ve bunların 300 bin kadarı yaşam kaybıyla sonuçlanmaktadır. ${ }^{12}$ Sonbahar ve kış aylarında, inflüenza enfeksiyonları artarak yaşılıları pnömokok enfeksiyonlarına karşı duyarlı hale getirmektedir. ${ }^{13}$ Pnömokok enfeksiyonlarının; menenjit, akut otitis media ve invaziv pnömokok hastalığı gibi komplikasyonlara yol açtığı ve korunmada aşılanmanın etkinliği daha önce gösterilmiştir. ${ }^{14}$
$\mathrm{Bu}$ sebeplerden ötürü yaşlilarda CDC (Center for Disease Control and Prevention) tarafından önerilen influenza ve pnömokok gibi hastalıklara karşı korunma stratejileri önerilmiştir. ${ }^{15}$

Dünya'da 75 farklı ülkede, yaşlılara yönelik bağışıklama programları yürütülmektedir. Ülkemizde de benzer şekilde bir program mevcuttur. $\mathrm{Bu}$ program dahilinde ülkemizde 65 yaş üzerine önerilen aşılar; influenza, pnömokok, hepatit A ve B, tetanos ve herpes zoster aşılarıdır. CDC önerileri de aynı aşılama programını önermektedir. ${ }^{15,16}$

\section{Bağıșıklamanın Önemi}

Yaşlıların yaklaşık \%80'i en azından bir kronik hastalığa, \%25'i üç veya daha fazla kronik hastalığa sahiptir. Yaşlıların fonksiyonel durumları, mekanik bariyer fonksiyonlarının bozulması, bakımevlerinde artabilen bulaşma riski ve "İmmunosenescence" gibi nedenlere bağlı inflüenza ve pnömokok gibi birçok enfeksiyona eğilim, yaşlılarda mortalitenin önemli nedenlerindendir. Bu yüzden yaşlılarda, bu etkenlere karşı aşılanmanın önemi hem komplikasyonlar hem de yaşlıların günlük sosyal ve yaşam aktivitelerini sürdürebilmek için daha konforlu bir yaşam sürmesi açısından önemlidir. İmmün fonksiyon azaldıkça enfeksiyon hastalıkları riski de artmaktadır. Ancak $\geq$ 65 yaş gurubundaki kişilerin aşı yanıtları farklılık gösterebilmektedir. Bazı çalışmalarda 50-65 yaş arasındaki aşı yanıtının daha iyi olduğu belirlenmiştir. $\mathrm{Bu}$ nedenle inflüenza ve pnömokok aşısı için bazı ülkelerde farklı yaşlara göre risk eksenli aşılama stratejileri uygulamaktadır. ${ }^{17}$

Yaşlılarda enfeksiyon hastalıklarına eğilimin nedenleri:

- $\quad$ İmmün yaşlanma (İmmunosenescence)

- S S S $\quad$ eşlikla eden komorbiditelerin varlığı

(Diyabetes mellitus, solunum sistemi hastalıkları ya da kalp yetmezliği gibi sistemik hastalıklar)

- Mekanik bariyer fonksiyonlarının bozulması

- Bakımevlerinde ya da toplu yaşam alanlarında artan bulaşma riski

- $\quad$ Çeşitli nedenlere bağlı yetersiz ya da kötü beslenme 
- Çalışma hayatından uzaklaşma ya da komorbiditeler nedeni ile yetersiz fiziksel aktivite

\section{Aşı yanıtının oluşması}

İmmün yanıtın sağlanması, aktif ve pasif olarak gerçekleştirilebilir. Aktif bağışıklama, vücuda verilen antijene karşı antikor yanıtı oluşturulması ile gerçekleştirilirken pasif bağışıklama da ya hastalığı önceden geçirip iyileşen ya da aktif bağışıklamayla antikor ya da antitoksin yanıtı oluşan kişilerin serumundan elde edilen immünglobinlerin kişiye verilmesiyle sağlanabilir.

Aşıda bulunan antijen, immün sistemi uyararak dolaşan monosit ve dendritik hücrelerin aktive olmasını sağlar ve lenfatik yoldan en yakın lenf nodlarına ulaşır. $\mathrm{Bu}$ süreçte $\mathrm{T}$ ve $\mathrm{B}$ lenfositlerinin aktivasyonu ile antikor yanıtı başlar. ${ }^{18}$ Aşılama ya da toksoid uygulanmasıyla T4 lenfositlerin farklı subgurupları aktive olmaktadır. Monosit ve makrofajlar ile iş birliği yapan Th1, antikor üretimi için B-lenfositler ile iş birliği yapan Th2 ve henüz fagosite olmamış mikroorganizmalara karş1 sitokin salgılayan Th17 aktive olmaktadır. Foliküler B hücreleri de IL-21 stimülasyonuna neden olarak B lenfositlerin farklılaşmasıyla bellek özelliği olan B hücreleri ve antikor salgılayan plazma hücreleri oluşur ancak yaşlılarda timusun involüsyonu ile $\mathrm{T}$ hücrelerinin sayısında ve CD4/CD8 oranında azalma yaşanmakta, antikor yanıtı sağlayan B-hücreleri ve antijen sunumundan sorumlu dendritik hücreler olumsuz etkilenmektedir.

Protein yapılı aşılar hem B hem de T hücrelerini aktive ederken polisakkarit yapılı olanlar yalnızca $\mathrm{B}$ hücrelerini aktive ederler. $\mathrm{Bu}$ nedenle polisakkarit yapılı aşılarla hücresel immüniteyi sağlayan T hücreleri aktive olmadığından tekrar aşı dozlarına gereksinim olan kısa süreli ve zayıf bir antikor yanıtı oluşur. Polisakkarit yapının proteinle konjuge edilmesi $\mathrm{T}$ hücrelerinin de uyarılması sağlanabilmektedir.19,20

\section{İnfluenza Aşısı}

"CDC" tarafindan herhangi bir komorbidite olmasa bile 65 yaş ve üzeri kişilere inflüenza aşısı önerilmektedir. İnfluenza kaynaklı ölümlerin \%90'1, 65 yaş ve üzerindeki kişilerde görülmektedir. Bu nedenle yalnızca yaşlılara değil onlarla aynı ortamda yaşayan ya da bakım veren kişilere de her yıl bir doz influenza aşısının deltoid kasa yapılması önerilmektedir. Avrupa'da yaşlılarda en yüksek influenza aşılanması oranı \%77 ile Hollanda, en düşük aşılanma \%1 ile Estonya'da sağlanmıştır. ${ }^{11,21}$ Türkiye'nin batı bölgesinde/batısındaysa bu popülasyonda influenza aşılanma oranı \%15 iken Kuzeydoğu Anadolu'da yaşlı popülasyonun influenza aşılanma oranı \%12,3 olduğu belirlenmiştir. ${ }^{22,23}$ Oysaki aşılanmayla kontrol altına alınan enfeksiyonlar arasında, influenza ön sıralardadır. İnfluenza enfeksiyonu, genç kişilerde çoğunlukla birkaç günde düzelebilirken yaşlılarda mortalite ve morbidite ile sonuçlanabilmektedir. ${ }^{24}$ Tayvan'da kış sezonunda influenza aşısı yapılanlarda, aşı yapılmayanlara göre hem pnömoni hem de akut koroner sendrom oranları daha az bulunmuştur. ${ }^{25}$ Yaşlida, akut koroner sendrom gibi olaylar geliştiğinde tanısal süreç işlemlerinde renal yetersizlik gibi diğer sistemik sekonder olayların gelişimiyle birden fazla komorbid hastalık riski de artmaktadır. ${ }^{26}$ Geniş sayılı bir çalışmada da, 20002009 seneleri arasında influenza sezonlarında influenza aşısının yalnızca mortalite oranlarını azaltmakla kalmayıp bunun yanında hastane yatış oranlarını da düşürdüğü belirlenmiştir. ${ }^{27}$

\section{Pnömokok Aşısı}

Pnömokok enfeksiyonu, 50 yaşında artmaya başlamaktadır. Bu oran 65 yaşından itibaren artarak ciddi komplikasyonlar ve mortaliteye neden olmaktadır. Pnömokok aşıları, 13 değerli konjüge aşı (PCV13) ve 23 değerli polisakkarit aşı (PPSV23) olmak üzere iki tiptir. 2014 yılından itibaren her ikisinin de yapılması önerilmektedir. ${ }^{28,29}$

- $\quad 65$ yaş öncesinde bir doz PPSV23 aşıs1 yapılmış ve aradan bir yıl geçmiş birisi şimdi $\geq 65$ yaşında ise bir doz PCV13 uygulanır, 6-12 ay sonra bir doz PPSV23 yapılarak beş yılda bir tekrarlanır.

- Daha önce hiçbir pnömokok aşısı yapılmamış $\geq 65$ yaşında olan sağlıklı birisi için bir doz PCV13, 6-12 ay sonra bir doz PPSV23 yapılır.

- $\quad$ Daha önce bir doz PPSV23 pnömokok aşıs1 yapılmış $\geq 65$ yaşında olan sağlıklı birisi için 12 ay sonra yalnızca bir doz PCV13 uygulanır.

CAPITA (Community Acquired Pneumonia immunization Trial in Adults) çalışmasında, PCV13 pnömokok aşısının etkinliği gösterilmiş ve başka bir çalışmada invaziv pnömokkal hastalıkların \%38'de pnömokok 
PPSV23 aşısının koruyabileceği serotiplerden kaynaklandığı tespit edilmiştir. ${ }^{30,31}$ İskoçya' da 20032004 yılında PPSV23 aşısıyla yaşlılarda invaziv pnömokok hastalığının üçte bir oranında azalmıştır. Benzer olarak İsveç'de yapılan çalışmada, influenza ve 23-valent pnömokok aş1s1 uygulananlarda aşılanmayanlara göre hem influenza olgularında hem de invaziv pnömokok hastalık oranlarında önemli derecede düşme belirlendi. Yaşlıların çoğunlukla solunum sistemi enfeksiyonlarıyla buna bağlı sekonder enfeksiyonlar ve kardiyovasküler nedenleriyle acil olarak hospitalize edildiğinden inflüenza ve pnömokok aşısı sağlık maliyet yükünü azaltması bakımından da önemlidir. ${ }^{14,32-34} \mathrm{Bu}$ önemli verilere rağmen pnömokok aşısı aşılanma oranı oldukça düşüktür. Önceki belirtilen araştırmada, 65 yaş ve üzeri kişilerde bu oran yalnızca $\% 0,9$ olarak belirlenmiştir. $^{23}$

\section{SONUÇ}

Enfeksiyon hastalıkları ve komplikasyonlarından korunmak, yaşlıların fonksiyonel iyilik halini ve sağlıklı yaşlanmalarını sağlar. Yeterli influenza ve pnömokok aşılama stratejilerinin sağlanmasıyla aşıların etkinliğinin daha da arttırılması bakımından önem arz etmektedir. Yaşlıların aşılar konusunda bilgilendirilmeleri, telkin edilmeleri ve birlikte yaşadıkları kişilerin de aşılanmaları önemlidir. 65 yaş ve üzeri kişiler, çoğunlukla/genellikle solunum sistemi, enfeksiyon hastalıkları ya da kardiyovasküler olaylar nedeniyle hospitalize edildikleri düşünüldüğünde yalnızca morbidite ve mortalite açısından değil aynı zamanda sağlık maliyetlerinin azaltılması da influenza ve pnömokok gibi enfeksiyonlara karşı aşılanmada önem arz etmektedir. Genel olarak influenza ile ilişkili hastane yatışların ve ölümlerin \%90'ını yaşlı nüfusun oluşturduğu dikkate alındığında yaşlılarda aşılanma oranlarının arttırılması gerekmektedir.

\section{KAYNAKLAR}

1- World Health Organization. Ageing and health: Fact sheet, http://www.who.int/news-room/fact- sheets/detail/ageing-and-health [Accessed $23 \mathrm{Apr}$ 2019]

2- Turkish Statistical Institute. Main statistics results of 2017, http://www.tuik.gov.tr. [Accessed $24 \mathrm{Apr}$ 2019]

3- Montecino-Rodriguez E, Berent-Maoz B, Dorshkind K. Causes, consequences, and reversal of immune system aging. J Clin Invest 2013; 123(3): 958-65.

4-Weinberger B, Herndler-Brandstetter D, Schwanninger A, Weiskopf D, GrubeckLoebenstein B. Biology of immune responses to vaccines in elderly persons. Clin Infect Dis 2008; 46(7): 1078-84.

5- Weinberger B, Grubeck-Loebenstein B. Vaccines for the elderly. Clin Microbiol Infect 2012; 18(5): $100-8$.

6- Tasselli L, Wei Z, Katrin FC. "SIRT6: novel mechanisms and links to aging and disease." Trends in Endocrinology \& Metabolism 2017; 28(3): 16885

7- Sharma A, Diecke S, Zhang WY, Lan F, He C, Mordwinkin NM et al. The role of SIRT6 protein in aging and reprogramming of human induced pluripotent stem cells. The Journal of biological chemistry. 2013; 288(25): 18439-47.

8- Dominy JE Jr, Lee Y, Jedrychowski MP, Chim H, Jurczak MJ, Camporez JP et al. The deacetylase Sirt6 activates the acetyltransferase GCN5 and suppresses hepatic gluconeogenesis. Molecular cell. 2012; 48(6): 900-13

9- Xu Z, Zhang L, Zhang W, Meng D, Zhang H, Jiang $Y$ et al. SIRT6 rescues the age related decline in base excision repair in a PARP1-dependent manner. Cell cycle. $2015 ; 14(2)$ : 269-76.

10- Ozkan O, Tural K. Changes in the Expression and the Role of Sirtuin 3 in Cancer Cells and in Cardiovascular Health and Disease. In: Uchiumi, F ed. Gene Expression and Regulation in Mammalian Cells-Transcription Toward the Establishment of Novel Therapeutics. London: IntechOpen, 2018:249-326.

11- Haq K, McElhaney JE. Immunosenescence: Influenza vaccination and the elderly. Curr Opin 
Immunol. 2014; 29: 38-42. doi: 10.1016/j.coi.2014.03.008.

12-Lang PO, Aspinall R. Vaccination in the elderly: what can be recommended? Drug Aging 2014; 31(8): 581-99.

13-Ludwig E, Bonanni P, Rohde G, Sayiner A,Torres A. The remaining challenges of pneumococcal disease in adults. Eur Respir Rev 2012; 21(123): 57-65.

14-Mooney JD, Weir A, McMenamin J, Ritchie LD, Macfarlane TV, Simpson CR et al. The impact and effectiveness of pneumococcal vaccination in Scotland for those aged 65 and over during winter 2003/2004. BMC Infect Dis 2008; 8(1):53.

15-CDC. Recommended Immunizations for Adults: By Age, https://www.cdc.gov/vaccines/schedules/downloads /adult/adult-schedule-easy-read.pdf. [Accessed 23 Apr 2019]

16.Koldaş Z. Yaşlı popülasyonda bağışıklama(aşılama). Turk Kardiyol Dern Ars 2017;45 (S5):124-127.

17- McElhaney E, Gavazzi G, Flamaing J, Petermans J. The role of vaccination in successful independent ageing. European Geriatric Medicine 2016; 7(2); 171-5.

18- Bacchetta R, Gregori S, Roncarolo MG. CD4+ regulatory $\mathrm{T}$ cells: mechanisms of induction and effector function. Autoimmun Rev 2005; 4(8): 4916

19- Weintraub A. Immunology of bacterial polysaccharide antigens. Carbohydr Res 2003; 338(23): 2539-47.

20- Lee CJ, Lee LH, Lu CS, Wu A. Bacterial polysaccharides as vaccines-immunity and chemical characterization. Adv Exp Med Biol 2001; 491: 45371.

21-Triglav TK, Poljak M. Vaccination indications and limits in the elderly. Acta Derm-Venereol 2013; 22(3): $65-70$.

22- Polat HH, Öncel S, Turhan Ö, Akcan A, Eravşar $\mathrm{K}$, Yalcin $\mathrm{AN}$. İnfluenza vaccinatıon in 65 and over age adults in Antalya/Turkey. Turk Geriatri Derg 2012; 15(4): 371-7.
23- Erdoğdu Hİ, Çatak B. Influenza, Pneumococcal and Herpes Zoster vaccination rates amongst people aged 65 years and older and related factors. Turkish Journal of Geriatrics 2018; 21(4): 498-06

24- Lang PO. Why influenza viruses continue to pose a significant threat to aging and aged populations worldwide. Curr Geriatr Rep 2014; 3(1): 56-65.

25- Huang $\mathrm{CH}$, Chao DY, Wu CC, Hsu SY, Soon $\mathrm{MS}$, Chang $\mathrm{CC}$ et al. Influenza vaccination and the endurance against air pollution among elderly with acute coronary syndrome. Vaccine 2016; 34(50): 6316-22.

26- Karabağ Y, Çağdaş M, Rencuzogullari I, Karakoyun S, Artaç İ, İliş D, Yesin M, Çiftçi H, Erdoğdu HI, Tanboğa IH. The C-Reactive Protein to Albumin Ratio Predicts Acute Kidney Injury in Patients With ST-segment Elevation Myocardial Infarction Undergoing Primary Percutaneous Coronary Intervention. Heart Lung Circ. 2018. doi: 10.1016/j.hlc.2018.08.009. [Epub ahead of print].

27- Wong K, Campitelli MA, Stukel TA, Kwong JC. Estimating influenza vaccine effectiveness in community-dwelling elderly patients using the instrumental variable analysis method. Arch Intern Med 2012; 172(6): 484-91.

28-Büke AÇ. Yaşlılarda bağışıklama. Ege Journal of Medicine 2015; 54: 35-40

29-Tomczyk S, Bennett NM, Stoecker C, et al. Use of 13-valent pneumococcal conjugate vaccine and 23 -valent pneumococcal polysaccharide vaccine among adults aged $\geq 65$ years: Recommendations of the Advisory Committee on Immunization Practices (ACIP). Centers for Disease Control and Prevention (CDC). MMWR Morb Mortal Wkly Rep 2014; 63(37): 822-5.

30-Webber C, Patton M, Patterson S, SchmoeleThoma B, Huijts SM, Bonten MJ. Exploratory efficacy endpoints in the community-acquired pneumonia immunization trial in adults (CAPiTA). Vaccine 2017; 35(9): 1266-72.

31- Chiou WY, Lee MS, Hung SK, Lin HY, Lo YC, Hsu FC et al. Effectiveness of 23-valent pneumococcal polysaccharide vaccine on elderly long-term cancer survivors: a population-based propensity score matched cohort study. BMJ open 2018; 8(5): e019364. 
32-Hedlund J, Christenson B, Lundbergh P, Örtqvist A. Effects of a large-scale intervention with influenza and 23-valent pneumococcal vaccines in elderly people: a 1-year follow-up. Vaccine 2003; 21(25-26): 3906-11.

33-Avcı S, Erdoğdu Hİ. Acil Servise Başvuran Geriatrik Hastaların Cinsiyete Göre Değerlendirilmesi. Kafkas J Med Sci 2017; 7(3): 209-13

34-Stoecker C. Incremental cost-effectiveness of modifying PPSV and PCV recommendations for adults age 50 and over. Presented at the Advisory Committee on Immunization Practices June 25, 2014 meeting, Atlanta, GA; 2014, http://www.cdc.gov/vaccines/acip/meetings/downlo ads/slides-2014-06/pcv13-02-stoecker.pdf

[Accessed 23 Apr 2019] 